УДК 004.056.5

\author{
В. В. Зоримо, О. Ю. АебеАсва \\ Одеський національний політехнічний університет \\ Проспект Шевченка, 1, 65044, Одеса, Україна \\ zorilovika@ukr.net; whiteswanhl@yahoo.com
}

\title{
Метод виявлення фацьсифікації у медичних зображеннях
}

У сучасному світі проблеми захисту інформачії є дуже важливими. Однією з проблем є захист цифррових сигналів від фальсифікачіï, зокрема - виявлення фальсифікаиії ичифрового зображення. Цифрові фотографії використовуються практично в усіх областях людської діяльносmi, у тому числі і в медицині. Медичні зображення можуть бути підроблені, наприклад, для зміни діагнозу, якщьо від иього залежить влаштування на роботу або отримання медичної страховки. У роботі запропоновано метод, щуо дозволяе виявити фальсифікацію ичифрового медичного зображення, виконану за допомогою клонування, в умовах постобробки клонованої області таким засобом як корекиія яскравості або при використанні розмиття всього зображення.

Ключові слова: ичифрове зображення, медичне изифрове зображення, порушення иілісності, клонування, розмиття зображення, корекиія яскравості, блоки складної форми.

\section{Вступ}

Через сучасну тенденцію використання цифрових сигналів (відео, зображення) в усе більшому числі сфер людської діяльності зростає актуальність методів виявлення порушення цілісності цифрових сигналів взагалі та цифрових зображень (ЦЗ) зокрема. Фальсифікації може бути піддане як зображення із побутовим сюжетом (підробка номерів автомобіля, поєднання на одному фото людей, які насправді не були поруч, тощо), так і медичні зображення. У випадку останніх їхня підробка може здійснюватися з різними намірами: приховання діагнозу, отримання страховки, візи тощо. Тому методи виявлення порушення цілісності цифрових зображень є актуальними і для медичних знімків. Виходячи з того, що цифрове відео представляє собою послідовність кадрів (цифрових зображень), то далі у статті мова йтиме про цифрові зображення, проте все сказане справедливе і для цифрового відео. Одним із найбільш поширених засобів порушення цілісності цифрових зображень є операція клонування, в ході якої відбувається заміна частини ЦЗ частиною того же ЦЗ. Найбільш поширеними засобами постобробки цифрового медичного зображення $є$ розмиття усього зображення та корекція яскравості клонованої області.

(C) В. В. Зорицо, О. Ю. Аебелєва

ISSN 1560-9189 Ресстрація, зберігання і обробка даних, 2015, T. 17, № 2 
Метою роботи є детектування порушення цілісності цифрового медичного зображення в умовах його постобробки шляхом розробки методу виявлення фальсифікації цифрового зображення.

Для досягнення поставленої у роботі мети необхідно вирішити наступні задачі.

1. Визначити найбільш ефективні методи виявлення клонування без постобробки і в умовах постобробки клонованої області та розмиття всього цифрового зображення.

2. Адаптувати вибрані методи для медичного цифрового зображення.

3. Розробити метод виявлення фальсифікації у медичних зображеннях.

\section{Основна частина}

Проблемі виявлення клонування присвячено багато сучасних публікацій [14]. У [1] запропоновано метод, який добре зарекомендував себе з точки зору інваріантності до афінних перетворень, проте не є спроможнім у випадку малого розміру клонованої області, а також при клонуванні об'єктів фонового наповнення. Метод [2] поступається методам [3,4] у швидкодії та точності, а методи [3, 4] знайшли своє відображення у [5], де доповнюють один одного та дозволяють не тільки швидко, але й точно знайти клоновану область та їі прототип. Метод, наведений у [5], дозволяє знайти клоновану область, контури якої були розмиті за умови, що ії розмір становить хоча 61 блок $8 \times 8$, та зображення після фальсифікації збережено у форматі без утрат. Проте, якщо розміри клону малі, і розмиттю піддано усе зображення, то жоден із зазначених методів виявлення клонування не буде спроможним його виявити. У цьому випадку виявлення розмиття цифрового зображення дає змогу говорити про те, що підозрюваний файл не є оригінальним та не може бути використаний як достовірний документ. Серед сучасних методів виявлення розмиття найбільш ефективним $\epsilon$ метод [6], заснований на загальному підході до аналізу стану і технології функціонування інформаційної системи [7]. Це показано у [8] на основі проведеного аналізу ефективності даного методу порівняно з іншими аналогами. Серед сучасних методів виявлення клонування в умовах корекції яскравості є метод, приведений у $[9,10]$. Отже для розробки методу виявлення фальсифікацій у цифрових медичних зображеннях, які виконані за допомогою клонування, в умовах постобробки клонованої області таким засобом, як корекція яскравості або при використанні розмитті всього зображення, були використані методи [5, 6, 9].

Розглянемо специфіку використання даних методів для медичних зображень, серед яких знімки магнітно-резонансної томографії (МРТ) та ультразвукового дослідження (УЗД), рентгенівські знімки (рис. 1) та ін. Медичні знімки мають бути чіткими, в них не використовують ніяких художніх ефектів, макрозйомки тощо.

Однак для методу виявлення розмиття при роботі з медичними зображеннями є деяка специфіка. При перевірці зображень, які знято в режимі «макрозйомка», тобто сюжет яких представляє собою візуально чіткий об'єкт на візуально розмитому фоні, часто виникає хибна ідентифікація даного зображення як розмитого графічним редактором. Також хибна тривога може виникнути і тоді, коли зображення було стиснуто у форматі з утратами із коефіцієнтом якості $Q \leq 8$ згідно стандартів графічного редактора Adobe Photoshop [6]. У методі виявлення розмиття 
для таких випадків передбачена додаткова перевірка за допомогою проведення так званого експертного розмиття [8].

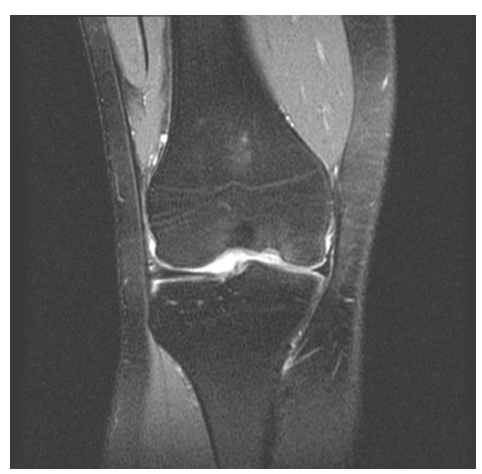

a)

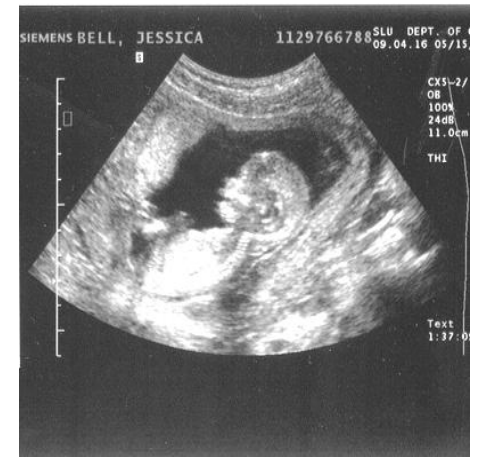

б)

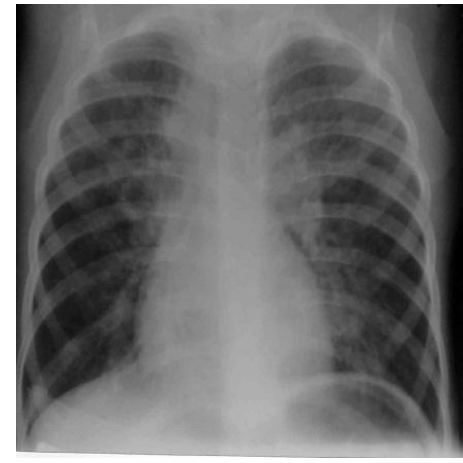

B)

Рис. 1. Приклади медичних зображень: а) знімок МРТ; б) знімок УЗД; в) рентгенівський знімок

Як вже було зазначено, при медичній зйомці не використовують таких художніх ефектів, вони носять документальний характер та завжди мають бути найвищої якості. Цей факт дозволяє зробити висновок про відсутність необхідності додаткової перевірки.

У зв'язку з цим у представленій роботі пропонується метод виявлення фальсифікації в медичних зображеннях. Основні кроки якого представлено нижче.

Крок 1. Пошук розмиття всього зображення.

1.1. $F_{i j}, i=1,2 \ldots,[n / 8], j=1,2 \ldots,[m / 8]$.

1.2. Побудувати матрицю швидкості росту $W 3$ елементами $w_{i j}$, $i=1,2 \ldots,[n / 8], j=1,2 \ldots,[m / 8]$, при цьому для визначення елементів $w_{i j}$ :

1.2.1. Для блоку $F_{i j}$ знайти сингулярний розклад: $F_{i j}=U_{i j} \sum_{i j} V_{i j}^{T}$, де $U_{i j}, V_{i j}$ ортогональні $8 \times 8$-матриці лівих і правих сингулярних векторів $F_{i j}$ відповідно, $\sum_{i j}=\operatorname{diag}\left(\sigma_{1}, \ldots, \sigma_{8}\right)-$ матриця сингулярних чисел, $\sigma_{1} \geq \ldots \geq \sigma_{8} \geq 0$;

1.2.2. Для $\sigma_{l}, l=4, \ldots, 8$ блоку $F_{i j}$ побудувати лінійну апроксимуючу функцію $y=a x+b$

\subsection{3. $w_{i j}=a$.}

1.3. Побудувати вектор середніх значень для $W$, визначити $V M V_{c}, V M V_{m}$.

\section{4. Якщчо $V M V_{c}>1$,}

то зображення не розмите, перейти до кроку 2 ,

інакше зображення розмите, закінчити роботу методу.

Крок 2. Пошук областей клонування без постобробки.

2.1. Розбити матрицю $F$ зображення на $8 \times 8$-блоки $F_{i j}, i=1,2 \ldots,(n-7)$, $j=1,2 \ldots,(m-7)$, що перетинаються так, щоб кожен блок відрізнявся від сусіднього на один стовбець (рядок). 
2.2. Побудувати матрицю $S$ з елементами $s_{i j}=\sum_{k=1}^{4} \sigma_{k}, \quad i=1,2 \ldots,(n-7)$, $j=1,2 \ldots,(m-7)$, де $\sigma_{1}, \sigma_{2}, \sigma_{3}, \sigma_{4}$ - найбільші сингулярні числа відповідного блоку $F_{i j}, i=1,2 \ldots,(n-7), j=1,2 \ldots,(m-7)$.

2.3. Побудувати матрицю клонування 3 елементами $c_{i j}, i=1,2 \ldots,(n-7)$, $j=1,2 \ldots,(m-7) ; c_{i j}$ відповідає блоку $F_{i j}$ цифрового зображення. Для визначення $c_{i j}$ порівняти $s_{i j}$ попарно з усіма елементами $S$ :

Якщо для $s_{i j}$ знайдеться елемент $s_{k l}, k \neq i, l \neq j$, матриці $S$, что $s_{i j}=s_{k l}$,

mo $c_{i j}=1$,

інакие $c_{i j}=0$.

Елементи $c_{i j}=1$ матриці $C$ відповідають клонованим блокам цифрового зображення.

2.4. Сформувати матриці нового зображення $F^{\prime}=\bigcup c_{i j}$, що містить знайдені клоновані блоки.

2.5. Якщо $F^{\prime} \neq \varnothing$, то перейти до кроку 3 , інакше перейти до кроку 4.

Крок 3. Уточнення області клонування.

3.1. Отримати координати $\left(x_{1}, y_{1}\right)$ та $\left(x_{2}, y_{2}\right)$ прямокутної області зі знайденими областями клонування з матриці $F^{\prime}$.

3.2. Сформувати матрицю яскравості $Y^{\prime}$ отриманої прямокутної області за координатами $\left(x_{1}, y_{1}\right)$ та $\left(x_{2}, y_{2}\right)$.

3.3. Розбити матрицю яскравості $Y^{\prime}$ на блоки $D=\left\{d_{1}, d_{2}, \ldots, d_{t}\right\}$, що перетинаються, $\bigcup_{j=1}^{t} d_{j}=Y^{\prime}$ розміром $p \times p$, res $=\varnothing$.

3.4. Для кожної пари блоків $d_{i}, d_{j}, i=1, \ldots, t, j \quad i+1, \ldots, t$ отримати нестандартні розбиття $d_{i}^{r}$ та $d_{j}^{r}$ відповідно, де $r$ - номер розбиття. Для кожного розбиття:

3.4.1. Обчислити міру близькості $\delta=\operatorname{Correlation}\left(d_{i}^{r}, d_{j}^{r}\right)$;

3.4.2. Знайти пари блоків $d_{i}^{r}$ та $d_{j}^{r}$, що відповідають клонам і їхнім прообразам, шляхом аналізу значення міри близькості $\delta$;

3.4.3. Якщо пари блоків $d_{i}^{r}$ та $d_{j}^{r}$, відповідають клонам і їхнім прообразам, запам'ятати: $\operatorname{res}=\operatorname{res} \bigcup d_{i}^{r} \bigcup d_{j}^{r}$.

3.5. Сформувати зображення $F^{\prime \prime}=r e s$. Закінчити роботу методу.

Крок 4. Пошук областей клонування в умовах корекції яскравості.

4.1. Розбити матрицю яскравості $Y^{\prime \prime}$ аналізованого ЦЗ, на множину пересічних $p \times p$ блоків: $T=\left\{t_{1}, \ldots, t_{s}\right\}$, таких, що: $\bigcup_{i=1}^{s} t_{i}=Y^{\prime \prime}$ (кожен наступний блок $c_{i}$ відрізняється від попереднього $t_{i-1}$ зміщенням на 1 піксель вправо, вліво, вниз або вгору), res $=\varnothing$. 
4.2. Для кожної пари блоків $t_{i}, t_{j}, \quad i, j=1, \ldots, s, \quad i \neq j$, визначити сингулярні спектри $\sigma_{1}^{(i)}, \ldots, \sigma_{p}^{(i)} ; \sigma_{1}^{(j)}, \ldots, \sigma_{p}^{(j)}$ відповідно.

4.2.1. Знайти пари блоків $\bar{t}_{i}, \bar{t}_{j}$, підозрілі на належність областям клону і його прообразу, шляхом аналізу ступеня близькості/співпадіння пар відповідних їм СНЧ: $\sigma_{k}^{(i)}$ и $\sigma_{k}^{(j)}, 2<k \leq p$, для яких обчислити $\bar{k}=\left|\sigma_{1}^{(i)}-\sigma_{1}^{(j)}\right| / p$

4.2.2. 3 урахуванням $k \in[\bar{k}-P, \bar{k}+P], k \in Z$, уточнити отримане значення $\bar{k}$ проведеної корекції яскравості.

4.2.3. 3 урахуванням можливих значень $\bar{k}$ визначити, чи $є \bar{t}_{i}, \bar{t}_{j}$ блоками області клону і його прообразу.

4.2.4. Якщо пари блоків $\bar{t}_{i}, \bar{t}_{j}$, відповідають клонам і їхнім прообразам, запам'ятати: $r e s=r e s \bigcup t_{i} \bigcup t_{j}$.

4.3. Сформувати зображення $F^{\prime \prime \prime}=r e s$. Закінчити роботу методу.

Результат роботи розробленого методу можна бачити на рис. 2.

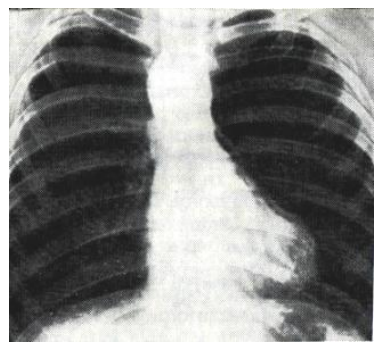

a)

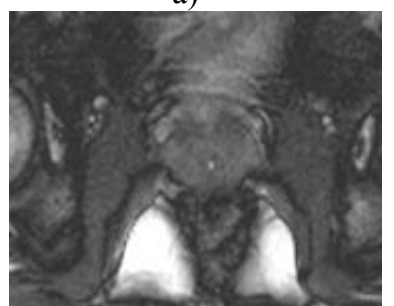

д)

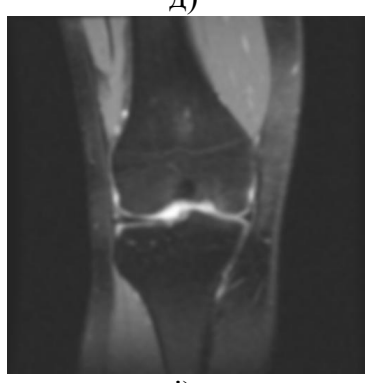

i)

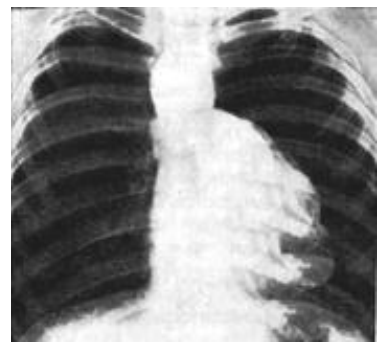

б)

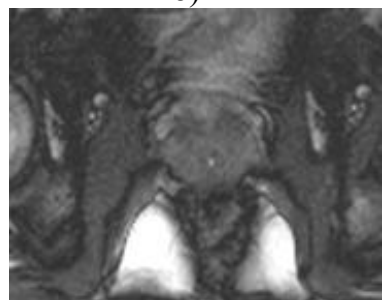

e)

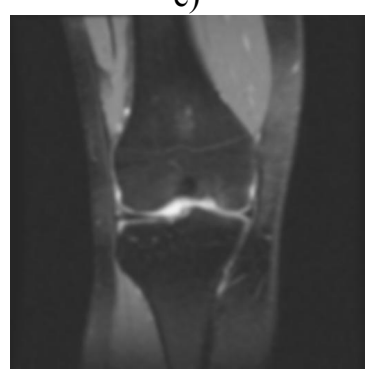

к)

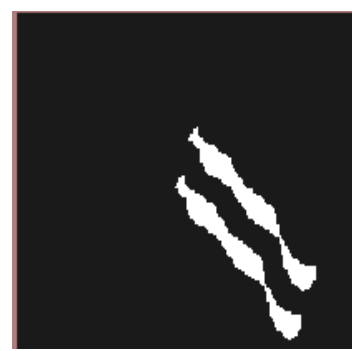

B)

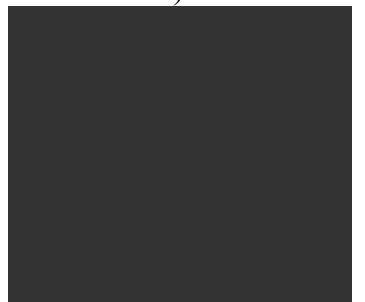

ж)

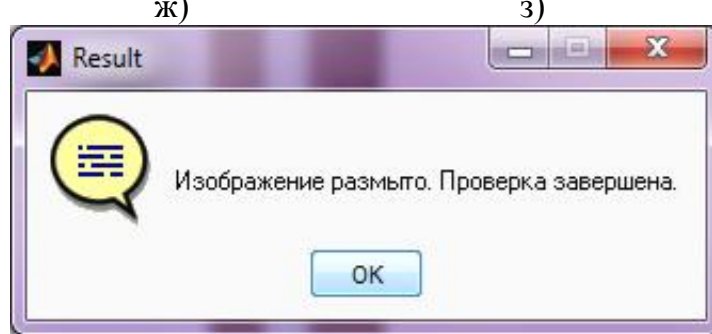

л)

Рис. 2. Результати роботи розробленого методу: а), д), і) — орігінальні зображення; б), е), к) - фальсифіковані зображення; в), ж) - результати кроку виявлення областей клонування без постобробки; г) результат кроку уточнення області клонування; з) результат кроку виявлення областей клонування в умовах корекції яскравості; л) результат кроку виявлення розмиття 


\section{Висновки}

Визначено найбільш ефективні методи виявлення клонування без постобробки і в умовах постобробки клонованої області засобами корекції яскравості пікселів і розмиття всього цифрового зображення. Розроблено метод виявлення фальсифікації у медичних зображеннях, який дозволяє виявляти факт розмиття всього зображення та локалізувати область клонування в умовах відсутності постобробки та в умовах корекції яскравості клонованої області.

Уся необхідна інформація для роботи даного методу надається матрицею підозрюваного цифрового зображення. На кожному кроці роботи методу виводиться результат його роботи у вигляді повідомлення про розмиття або формуються зображення з виявленими областями фальсифікації.

1. Shivakumar B.L. Detection of Region Duplication Forgery in Digital Images Using SURF / B.L. Shivakumar, Lt. Dr. S.Santhosh Baboo // IJCSI International Journal of Computer Science Issues. 2011, July. - Vol. 8, N 1. - Issue 4. - P. 199-205.

2. Fridrich $J$. Detection of copy-move forgery in digital images [Электронный pecypc] / J. Fridrich, D. Soukal, and J. Lukas // In Proc. of the Digital Forensic Research Workshop. - Cleveland, OH 2003. - Режим доступа: http://www.ws.binghamton.edu/fridrich/research/ copymove.pdf.

3. Зорило В.В. Выявление клонирования как фальсификации цифрового изображения / В.В. Зорило // Вісник Національного технічного університету «ХПІ»: зб. наук. праць. - Тематичний випуск «Системний аналіз, управління та інформаційні технології». - Х.: НТУ «ХПІ», 2011. № $35-$ C. 31-38.

4. Лебедева Е.Ю. Исследование метрик используемых при обнаружении клонированных участков изображений в задачах выявления фальсификации / Е.Ю. Лебедева, Ю.Ф. Лебедев // Вісник національного технічного університету «ХПІ». — 2011. — № 35. — С. 25-31.

5. Зорило В.В. Комплексній метод выявления и локализации областей клонирования в цифрових изображениях / В.В. Зорило, Е.Ю. Лебедева // Праці Одеського політехнічного університету. — 2015. - Вип. 1(45). - С. 101-105.

6. Кобозева А.А. Анализ информационной безопасности: монография / А.А. Кобозева, В.А. Хорошко. - К.: ГУИКТ, 2009. — $251 \mathrm{c}$.

7. Зорило В.В. Методы повышения эффективности выявления нарушения целостности цифрового изображения / В.В. Зорило // Науково-технічний збірник «Правове, нормативне та метрологічне забезпечення системи захисту інформації в Україні». — 2013. — № 1(25). — С. 75-81.

8. Зорило В.В. Метод підвищення ефективності виявлення порушення цілісності цифрового зображення: дис. канд. техн. наук: 05.13.21 / Зорило Вікторія Вікторівна. - К., 2013. — 127 с.

9. Кобозева A.A. Основы метода выявления клонированных участков изображения, подвергнутых коррекции яркости / А.А. Кобозева, Е.Ю. Лебедева // Сучасна спеціальна техніка. - 2013. —№ 3. - С. 17-24.

10. Кобозева А.А. Принципы обнаружения клонированных участков, подвергнутых коррекции яркости / А.А. Кобозева, Е.Ю. Лебедева, В.В. Зорило // Матеріали Міжнародної науковопрактичної конференція «Інформаційні управляючі системи та технології». — 2013. - С. 167-169. 